\title{
Acil Serviste Patoloji Saptanmayan Elektrokardiyografilerin Tekrar Yorumlanması ve Çıkan Sonuçların Analizi
}

\author{
Yalçın KATI ${ }^{1}$, Vahide Aslıhan DURAK ${ }^{2}$, Erol ARMAĞAN ${ }^{2}$, Halil KAYA $^{3}$ \\ 1 İnegöl Devlet Hastanesi, Acil Servis Kliniği, Bursa. \\ 2 Bursa Uludağ Üniversitesi Tıp Fakültesi, Acil Tıp Anabilim Dalı, Bursa. \\ 3 Şevket Yılmaz Eğitim ve Araştırma Hastanesi, Acil Tıp Kliniği, Bursa
}

\section{ÖZET}

Acil servise başvuran hastaların patolojilerinin değerlendirilmesinde elektrokardiyografi önemli bir unsurdur. Elektrokardiyografinin doğru ve zamanında yorumlanması, potansiyel olarak yaşamı tehdit eden kardiyovasküler hastalıklar ve elektrolit değişiklikleri için önemlidir. Tanıda yeni ve pahalı teknolojik gelişmelere karşın, elektrokardiyografi, akut miyokard infarktüsü tanısında hem invaziv olmaması hem de ucuz olması nedeniyle belirgin ve hayati rolünü sürdürmektedir. Çalışmamıza 01.12.2015 - 30.05.2016 tarihleri arasında bir Eğitim ve Araştırma Hastanesi Acil Tıp Kliniği’ne başvuran, triaj alanı dikkate alınmaksızın değerlendiren doktoru tarafından elektrokardiyografi çekilmesi uygun görülmüş ve elektrokardiyografilerinde acil patoloji saptanmayan hastalar dahil edilmiştir. Çalışma protokolü prospektif, tanımlayıcı ve gözlemsel olarak tasarlanmıştır. Çalışmaya dahil edilen hastaların \%93.6'sında herhangi bir kronik hastalık bulunmadığı, \%4.9'unun hipertansiyon hastası olduğu sonucuna varılmıştır. Çalışmaya alınan elektrokardiyografilerin \%96.1 oranında sinüs ritminde olduğu saptanmıștır. En sık olarak \%9,8 oranla P dalga morfolojisinde patolojik bulgular tespit edilmiştir. En sik saptanan patolojik tanı $\% 9,2$ ile $P$ mitrale olmuştur. Değerlendiren doktorlar bakımından ritm, hız, PR, QTc, Aks, P dalgası ve ST segmenti değerlendirmeleri oranları arasındaki farklılığın istatistiksel olarak anlamlı olduğu görülmüstür. Acil servislerde çalıșmakta olan tüm hekimlerin için elektrokardiyografi değerlendirme eğitimi almış olmak son derece önemlidir. Bu eğitimler hem atlanabilecek veya yanlış tanı koyulabilecek elektrokardiyografilerin daha doğru değerlendirilmesini hem de klinik olarak önemsenmeyecek patolojik bulguların hakkında farkındalık sağlayarak doğru polikliniklere yönlendirip koruyucu sağlık hizmeti verilmesini sağlamaya yardımcı olacaktır.

Anahtar Kelimeler: Acil servis. Elektrokardiyografi. Patolojik bulgu.

The Re- Interpretation and Analysis of Results of Non-Pathological Electrocardiographies in

Emergency Department

\begin{abstract}
Electrocardiography (ECG) is an important factor in the evaluation of the pathology of patients who are referred to the emergency department. Correct and timely interpretation of electrocardiography is important for potentially life threatening cardiovascular diseases and electrolyte changes. Despite new and expensive technological developments in diagnosis, electrocardiography continues to be evident and vital because it is both non-invasive and inexpensive in the case of acute myocardial infarction. In our study, the patients with no pathologic electrocardiography findings in a Training and Research Hospital emergency medicine department without consideration of the triage area, (between 01.12.2015 - 30.05.2016) were included The study protocol was designed as prospective, descriptive and observational. As results, 93.6\% of the patients had no chronic diseases and $4.9 \%$ were hypertensive patients. Electrocardiographies were detected as sinus rhythm in $96.1 \%$ of the patients. Pathological findings were found in $\mathrm{P}$ wave morphology as $9.8 \%$. The most frequent pathologic diagnosis was $\mathrm{P}$ mitrale as $9.2 \%$. The difference between ratios, rates, PR, QTc, Axis, P wave and ST segment ratings was found to be statistically significant in terms of the evaluating physicians. All physicians working in emergency departments should be provided with occasional electrocardiography training. These trainings will help to evaluate electrocardiographies that can be skipped or misdiagnosed as well as to provide correct healthcare services by providing accurate awareness of pathologic findings that will not be considered clinical clinically.
\end{abstract}

Key Words: Emergency service. Electrocardiography. Pathological findings.

Geliş Tarihi: 22 Kasım 2018

Kabul Tarihi: 25 Şubat 2019

Dr. Vahide ASLIHAN DURAK

Bursa Uludağ Üniversitesi Tıp Fakültesi,

Acil Tıp Anabilim Dalı,

Bursa.

Tel.: 05324462512

E-posta: aslidurakis@hotmail.com
Acil servise birçok farklı sebepten hasta başvurmaktadır. Ülkemizde 110 milyon acil servis başvurusu mevcuttur. Acil servise başvuran hastaların patolojilerinin değerlendirilmesinde elektrokardiyografi (EKG) önemli bir unsurdur ${ }^{1}$. Bir EKG yorumlanırken gerekli süre ayrılmalı ve mutlaka hastanın eski EKG'leri göz önünde bulundurulmalıdır. Ancak başvuru yoğunluğu 
ve sirkülasyonun fazla yaşandığı acil servislerde, acil servis doktorunun doğru EKG yorumlaması için az bir süresi vardır ve çoğu zaman tek başına karar vermesi gerekmektedir.

EKG'nin doğru ve zamanında yorumlanması, potansiyel olarak yaşamı tehdit eden kardiyovasküler hastalıklar (KVH), ritim bozuklukları ve elektrolit değişiklikleri için önemlidir ${ }^{1}$.

Acil servis doktorunun EKG yorumlarken yaptığ 1 bir hata hasta tedavisi ile ilgili doğru olmayan bir kararın alınmasına veya yanlışlıkla hastanın taburcu olmasına neden olabilmektedir. Sıklıkla bakıp değerlendirdiğimiz EKG'lerde majör patolojiler aranmakta ve minör sayılabilecek patolojiler gözden kaçırılabilmekte veya tedaviyi etkilemeyeceğinden göz ardı edilebilmektedir. Bazı hastaların bu minör patolojiler saptanarak kardiyoloji takibine alınması gerekebilmektedir.

Çalışmamızın amacı; acil serviste değerlendirilen acil patoloji saptanmayan EKG'lerde saptanabilecek patolojilerin sıklığını kardiyoloji uzmanı eşliğinde saptamaktır.

\section{Gereç ve Yöntem}

Araştırmamız hastanemiz Tıbbi Etik Kurulunun 2011KAEK-25 2015/21-04 sayılı kararı ile izin alındıktan sonra başlamıştır.

Çalışma protokolü prospektif, tanımlayıcı ve gözlemsel olarak tasarlanmıştır.

Çalışma süresince hastanemiz acil servisine 227.881 hasta başvurusu olmuştur. Başvuran ve muayene edilen hastalar içinde EKG çekilen hasta sayısı 11.533' tür. EKG'leri değerlendirilen hastaların 1908 (\%16,5) tanesinde majör patoloji saptanmış ve çalışma dışı bırakılmıştır. $6342(\% 55)$ hastanın EKG' sinde minör patoloji saptanmış ve çalışma dışı bırakılmıştır. 1387 (\%12) hasta yaş grubu olarak 18 yaşından küçük olduğu için çalışmaya dahil edilmemiştir. $492(\% 4,3)$ hasta dosyasında EKG'ler eksik veya deforme olduğu için sağlıklı değerlendirilemeyeceğinden çalışmadan çıkartılmıştır. $404(\% 3,5)$ hasta dosyasında özgeçmiş sorgulamasında eksiklikler olduğu için çalışma dışı bırakılmıştır. Değerlendiren doktoru tarafindan EKG'sinde acil patoloji saptanmamış olan 1000 (\%8.7) hasta çalışmaya dahil edilmiştir.

Hastalara Nihon Kohden CardiofaxS ECG 1250-K model cihaz ile en az 10 sn'lik kayıt ile EKG çekimi; acil serviste çalışan hemşireler tarafindan yapılmıştır.

Hastaların cinsiyeti, yaşı, varsa kronik hastalıkları ve kullandıkları ilaçları kayıt altına alınmıştır. EKG analizinde, ritm, hız, aks, PR, QRS, QTc intervallerinin süreleri, P, T dalgalarının süre ve morfolojileri, ST segmentinin morfolojisi incelenmiştir.

Değerlendiren doktorlar da kıdem yılına göre 3 gruba ayrılmıştır: İlk grup 1-2. yıl acil tıp asistanları, ikinci grup 3-4. y1l asistanlar1, son grup ise acil tıp uzman doktorlarıdır. $\mathrm{Bu}$ gruplamanın amacı da saptanan patolojilerin klinik tecrübe ile ilişkisinin incelenmesidir.

Çalışmaya alınan EKG'ler daha önceden EKG değerlendirme kursu sertifikasına sahip acil tıp asistan ve uzmanlarından oluşan araştırma grubu tarafindan analiz edilmiştir. Elde edilen tüm sonuçlar değerlendirmenin doğruluğunun ve güvenirliliğinin ölçülmesi için altın standart olan bir kardiyoloji uzmanı tarafından kontrol edilmiştir.

\section{İstatistiksel Analiz}

Kategorik değişkenler sayı ve yüzde olarak özetlenmiştir. Kategorik değişkenler arasındaki farklılık karşılaştırmalarında 2x2 tablolarda Pearson Ki-Kare, RxC tablolarda ise Fisher Freeman Halton Test kullanılmıştır. Tüm veriler SPSS (Statistical Package for Social Sciences) 22.0 programı kullanılarak kaydedilmiş ve analiz edilmiştir. $\mathrm{p}<0.05$ ise, $\% 95^{\prime}$ lik güven aralığında, sonuç istatistiksel olarak anlamlı kabul edilmiştir.

\section{Bulgular}

Tablo I'de çalışmaya dahil edilen hastaların sosyodemografik özellikleri görülmektedir.

Tablo I. Hastaların Sosyo-Demografik Özelliklerine Ait Dağılım Tablosu

\begin{tabular}{|llrl|}
\hline & Sayı & $(\%)$ \\
\hline Yaş & & & \\
& $18-29$ & 283 & $(28.3)$ \\
& $30-49$ & 534 & $(53.4)$ \\
& $50-64$ & 106 & $(10.6)$ \\
& 65 ve Üstü & 77 & $(7.7)$ \\
Cinsiyet & & & \\
& Kadın & 494 & $(49.4)$ \\
& Erkek & 506 & $(50.6)$ \\
Kronik Hastalıklar & & \\
Hipertansiyon & 49 & $(4.9)$ \\
& Diyabet & 7 & $(0.7)$ \\
KAH & 5 & $(0.5)$ \\
& Diğer & 2 & $(0.2)$ \\
Yok & 936 & $(93.6)$ \\
Birden fazla hastalık & 1 & $(0.1)$ \\
Kullandığı Ilaçlar & & \\
Hipertansiyon & 49 & $(4.9)$ \\
DM & 7 & $(0.7)$ \\
KAH & 5 & $(0.5)$ \\
KOAH & 1 & $(0.1)$ \\
Diğer & 2 & $(0.2)$ \\
Yok & 936 & $(93.6)$ \\
\hline
\end{tabular}

Tablo II'de acil servise gelen hastaların patoloji saptanmayan elektrokardiyografilerin değerlendirilmesine ait bilgiler mevcuttur. Buna göre, yapılan analiz sonucunda, \%96,1 oranında ritm analizinin, sinüs ritminde olduğu sonucuna varmıştır. 
Tablo II. EKG Analizi Sonuçları

\begin{tabular}{|c|c|}
\hline & Sayı $(\%)$ \\
\hline \multicolumn{2}{|l|}{ Ritm } \\
\hline Sinüs Ritmi & 961 (96.1) \\
\hline Aritmik & $39(3.9)$ \\
\hline \multicolumn{2}{|l|}{ Hız } \\
\hline 59 ve Altı & 31 (3.1) \\
\hline $60-100$ & $910(91)$ \\
\hline 101 ve Üstü & $59(5.9)$ \\
\hline \multicolumn{2}{|l|}{ PR } \\
\hline 119 ms ve Altı & $79(7.9)$ \\
\hline $120-200 \mathrm{~ms}$ & 913 (91.3) \\
\hline 201 ms ve Üstü & $8(0.8)$ \\
\hline \multicolumn{2}{|l|}{ QRS } \\
\hline 110 ms ve Altı & $984 \quad(98.4)$ \\
\hline 111 ms ve Üstü & $16(1.6)$ \\
\hline \multicolumn{2}{|l|}{ QTC } \\
\hline $349 \mathrm{~ms}$ ve Altı & $0(0)$ \\
\hline $349-439 \mathrm{~ms}$ & 950 (95) \\
\hline 440 ms ve Üstü & 50 \\
\hline \multicolumn{2}{|l|}{ Aks } \\
\hline Normal Aks & $954 \quad(95.4)$ \\
\hline Sol Aks & $27 \quad(2.7)$ \\
\hline Sağ Aks & $16(1.6)$ \\
\hline Şiddetli Aks Sapması & $3(0.3)$ \\
\hline
\end{tabular}

P Dalgasını değerlendiren araştırmacı hekimler, \%90,2 oranında P dalgasının $110 \mathrm{~ms}$ 'nin altında olduğunu saptamıştır. ST segmenti incelendiğinde EKG'lerin \%97,6’sının izoelektrik hatta olduğunu saptanmıştır. $\mathrm{T}$ dalgası değerlendirmesi incelendiğinde, \%95,6 oranında 100-250 ms aralığında olduğu gözlenmiştir.

Çalışmaya alınan EKG'leri ilk değerlendiren doktorların dağılımları incelendiğinde ise, \%38,4'ünün 3-4 y1llık asistan olduğu, \%35,9'unun 1-2 y1llık asistan ve $\% 25,7$ 'sinin uzman doktor olduğu görülmüştür.

Tablo III'te görüldüğü üzere, acil patoloji saptanmayarak çalışmaya dahil edilen EKG'lerin incelenmesinin sonuçları, değerlendiren hekimlere göre dağılımı karşılaştırılmak istenmiştir. Buna göre değerlendiren doktorlar bakımından ritm $(\mathrm{p}<0.001)$, hiz $(\mathrm{p}<0.001)$, PR ( $<<0.001)$, QTc $(\mathrm{p}<0.001)$, Aks $(\mathrm{p}<0.001)$, P dalgası $(p<0.001)$ ve ST segmenti $(p=0.013)$ değerlendirmeleri oranları arasındaki farklılığın istatistiksel olarak anlamlı olduğu görülmüştür.

Tablo IV'de, acil patoloji saptanmayarak çalışmaya dahil edilen EKG'lerde saptanan patoloji sıklığı, değerlendiren hekimlere göre dağılımı karşılaştırılmak istenmiştir. Buna göre değerlendiren doktorlar bak1mindan ritm $(p<0.001), \operatorname{hiz}(p<0.001), P R(p=0.003)$, QTc $(p<0.001)$, Aks $(p<0.001)$ ve $P$ dalgası $(p<0.001)$ değerlendirmelerindeki oranları arasındaki farklılığın istatistiksel olarak anlamlı olduğu görülmüştür.
Tablo III. Acil Patoloji Saptanmayan EKG'lerin İnceleme Sonuçları, Değerlendiren Hekimlere Göre Dağılımı ve Karşılaştırılmas1

\begin{tabular}{|c|c|c|c|c|c|}
\hline & \multicolumn{4}{|c|}{ Değerlendiren Doktor } & \multirow[b]{3}{*}{$\mathbf{P}$} \\
\hline & \multicolumn{2}{|c|}{$\begin{array}{l}\text { Acil Tıp } \\
\text { Uzmanı }\end{array}$} & $\begin{array}{c}\text { 3-4 Yıl } \\
\text { Asistan }\end{array}$ & $\begin{array}{c}\text { 1-2 YII } \\
\text { Asistan }\end{array}$ & \\
\hline & Say & $(\%)$ & Sayı (\%) & Sayı (\%) & \\
\hline \multicolumn{6}{|l|}{ Ritm } \\
\hline Sinüs Ritmi & 228 & $(88.7)$ & $381(99.2)$ & $352(98.1)$ & \multirow{2}{*}{$<0.001^{*}$} \\
\hline Aritmik & 29 & $(11.3)$ & $3(0.8)$ & $7(1.9)$ & \\
\hline \multicolumn{6}{|l|}{ Hız } \\
\hline 59 ve Altı & 16 & $(6.2)$ & $3(0.8)$ & $12(3.3)$ & \multirow{3}{*}{$<0.001^{*}$} \\
\hline $60-100$ & 230 & $(89.5)$ & $368(95.8)$ & $312(86.9)$ & \\
\hline 101 ve Üstü & 11 & $(4.3)$ & $13(3.4)$ & $35(9.7)$ & \\
\hline \multicolumn{6}{|l|}{ PR } \\
\hline 119 ms ve Altı & 34 & $(13.2)$ & $21(5.5)$ & $24(6.7)$ & \multirow{3}{*}{$<0.001^{*}$} \\
\hline $120-200 \mathrm{~ms}$ & 223 & $(86.8)$ & $363(94.5)$ & 327 (91.1) & \\
\hline 201 ms ve Üstü & 0 & $(0)$ & $0(0)$ & $8(2.2)$ & \\
\hline \multicolumn{6}{|l|}{ QRS } \\
\hline $110 \mathrm{~ms}$ ve Altı & 252 & $(98.1)$ & $379(98.7)$ & $353(98.3)$ & \multirow{2}{*}{0.809} \\
\hline 111 ms ve Üstü & 5 & $(1.9)$ & $5(1.3)$ & $6(1.7)$ & \\
\hline \multicolumn{6}{|l|}{ QTC } \\
\hline $349 \mathrm{~ms}$ ve Altı & & $(0)$ & $0(0)$ & $0(0)$ & \multirow{3}{*}{$<0.001^{*}$} \\
\hline $349-439 \mathrm{~ms}$ & 249 & $(96.9)$ & $378(98.4)$ & $323(90)$ & \\
\hline 440 ms ve Üstü & 8 & (3.1) & $6(1.6)$ & $36(10)$ & \\
\hline \multicolumn{6}{|l|}{ AKS } \\
\hline Normal Aks & 256 & $(99.6)$ & $374(97.4)$ & $324(90.3)$ & \multirow{4}{*}{$<0.001^{*}$} \\
\hline Sol Aks & 1 & $(0.4)$ & $7(1.8)$ & $19(5.3)$ & \\
\hline Sağ Aks & & (0) & $0(0)$ & $16(4.5)$ & \\
\hline $\begin{array}{l}\text { Şiddetli Aks } \\
\text { Sapması }\end{array}$ & & (0) & $3(0.8)$ & $0(0)$ & \\
\hline \multicolumn{6}{|l|}{ P Dalgası } \\
\hline $110 \mathrm{~ms}$ ve Altı & 248 & $(96.5)$ & 347 (90.4) & 307 (85.5) & \multirow{3}{*}{$<0.001^{*}$} \\
\hline $\begin{array}{l}111 \text { ms ve Üstü } \\
\text { (P MiTRALE) }\end{array}$ & 9 & $(3.5)$ & $36(9.4)$ & 47 (13.1) & \\
\hline $\begin{array}{l}>2.5 \mathrm{mV} \text { ( } \mathrm{P} \\
\text { PULMONALE) }\end{array}$ & 0 & $(0)$ & $1(0.3)$ & $5(1.4)$ & \\
\hline \multicolumn{6}{|l|}{ ST Segmenti } \\
\hline ST Depresyonu & 6 & (2.3) & $5(1.3)$ & $13(3.6)$ & \multirow{3}{*}{$0.013^{*}$} \\
\hline İzoelektirik Hatta & 251 & $(97.7)$ & $379(98.7)$ & $346(96.4)$ & \\
\hline ST Elevasyonu & 0 & (0) & $0(0)$ & $0(0)$ & \\
\hline \multicolumn{6}{|l|}{ T Dalgası } \\
\hline $100-250 \mathrm{~ms}$ & 248 & $(96.5)$ & 368 (95.8) & $340(94.7)$ & \multirow{3}{*}{0.621} \\
\hline$>250 \mathrm{~ms}$ & 9 & (3.5) & $15(3.9)$ & $19(5.3)$ & \\
\hline Negatif T Dalgası & 0 & $(0)$ & $1(0.3)$ & $0(0)$ & \\
\hline
\end{tabular}

Ki-Kare Testi kullanıldı. Tanımlayıcı istatistikler sayı(\%) șeklinde verildi.

*: $\mathrm{p}<.05$ 
Tablo IV. Acil Patoloji Saptanmayan EKG'lerdeki Patoloji Sıklığı ve Değerlendiren Hekimlere Göre Dağılımının Karşılaştırılması

\begin{tabular}{|c|c|c|c|c|c|c|c|}
\hline & \multicolumn{6}{|c|}{ Değerlendiren Doktor } & \multirow[b]{2}{*}{$\mathrm{p}$} \\
\hline & \multicolumn{2}{|c|}{$\begin{array}{c}\text { Acil Tıp } \\
\text { Uzmanı } \\
\text { Sayı (\%) }\end{array}$} & \multicolumn{2}{|c|}{$\begin{array}{c}\text { 3-4 Yıl } \\
\text { Asistan } \\
\text { Sayı (\%) }\end{array}$} & \multicolumn{2}{|c|}{$\begin{array}{c}\text { 1-2 YIl } \\
\text { Asistan }\end{array}$} & \\
\hline \multicolumn{8}{|l|}{ Ritm } \\
\hline Patoloji Var & 29 & (11.3) & 3 & $(0.8)$ & & $(1.9)$ & \multirow{2}{*}{$<0.001^{*}$} \\
\hline Patoloji Yok & 228 & (88.7) & 381 & $(99.2)$ & 352 & (98.1) & \\
\hline \multicolumn{8}{|l|}{$\mathrm{H}$ Iz } \\
\hline Patoloji Var & 27 & (10.5) & 16 & $(4.2)$ & 47 & $(13.1)$ & \multirow{2}{*}{$<0.001$} \\
\hline Patoloji Yok & 230 & (89.5) & 368 & (95.8) & 312 & $(86.9)$ & \\
\hline \multicolumn{8}{|l|}{ PR } \\
\hline Patoloji Var & 34 & (13.2) & 21 & $(5.5)$ & 32 & $(8.9)$ & \multirow{2}{*}{0.003} \\
\hline Patoloji Yok & 223 & (86.8) & 363 & $(94.5)$ & 327 & (91.1) & \\
\hline \multicolumn{8}{|l|}{ QRS } \\
\hline Patoloji Var & 5 & (1.9) & 5 & $(1.3)$ & 6 & $(1.7)$ & \multirow{2}{*}{0.809} \\
\hline Patoloji Yok & 252 & (98.1) & 379 & (98.7) & 353 & (98.3) & \\
\hline \multicolumn{8}{|l|}{ QTC } \\
\hline Patoloji Var & 8 & (3.1) & 6 & $(1.6)$ & 36 & $(10)$ & \multirow{2}{*}{$<0.001^{*}$} \\
\hline Patoloji Yok & 249 & (96.9) & 378 & (98.4) & 323 & $(90)$ & \\
\hline \multicolumn{8}{|l|}{ Aks } \\
\hline Patoloji Var & 1 & $(0.4)$ & 10 & (2.6) & 35 & $(9.7)$ & \multirow{2}{*}{$<0.001^{*}$} \\
\hline Patoloji Yok & 256 & (99.6) & 374 & (97.4) & 324 & $(90.3)$ & \\
\hline \multicolumn{8}{|l|}{ P Dalgası } \\
\hline Patoloji Var & 9 & (3.5) & 37 & $(9.6)$ & 52 & (14.5) & \multirow{2}{*}{$<0.001^{*}$} \\
\hline Patoloji Yok & 248 & (96.5) & 347 & $(90.4)$ & 307 & $(85.5)$ & \\
\hline \multicolumn{8}{|l|}{ ST Segmenti } \\
\hline Patoloji Var & 6 & (2.3) & 5 & (1.3) & 13 & $(3.6)$ & \multirow{2}{*}{0.118} \\
\hline Patoloji Yok & 251 & (97.7) & 379 & (98.7) & 346 & $(96.4)$ & \\
\hline \multicolumn{8}{|l|}{ T Dalgası } \\
\hline Patoloji Var & 9 & (3.5) & 16 & $(4.2)$ & 19 & (5.3) & \multirow{2}{*}{0.543} \\
\hline Patoloji Yok & 248 & $(96.5)$ & 368 & $(95.8)$ & 340 & $(94.7)$ & \\
\hline
\end{tabular}

Ki-Kare Testi kullanıldı. Tanımlayıcı istatistikler sayı(\%) şeklinde verildi.

$*: \mathrm{p}<.05$

\section{Tartışma}

Acil servise başvuran hastaların tanı ve tedavi sürecinde EKG çok değerli bilgiler verebilir. Hastalardan göğüs ağrısı, nefes darlığı, inme, intoksikasyon, renal yetmezlik, hipertansiyon gibi birçok klinik durumda EKG çekilmesi istenir. Bu sayede myokard enfarktüsü, iskemi, elektrolit, ritm ve ileti bozuklukları hakkında bilgi edinilir. Hiç bir yan etkisi olmamasından dolayı her hastadan kolaylıkla istenebilecek bir tetkiktir.

Acil servis hasta yoğunluğu düşünüldüğünde, bu tetkik için bazen saniyeler içinde değerlendirilip karar vermek zorunda kalınmaktadır. Çoğunlukla da acil hekimleri major patolojileri hızlıca tarayıp yakalamaya odaklanmıştır. Kimi zaman klinik olarak önemi olmayan patolojik bulgular bilerek veya bilmeyerek muayene kartına not alınmamaktadır. Acil servis doktorları da başvuru sayılarının artması ve tedaviye zaman geçirmeden başlamak zorunda olduklarından EKG’yi en az hatayla analiz etmek zorundadırlar.
Kılıçaslan ve ark. bir üniversite hastanesi acil servisine başvuran hastaların demografik özelliklerini inceledikleri bir araştırmada tüm acil servis başvuruları yaş gruplarına göre incelendiğinde, en çok başvuru 20-29 yaş grubunda \%21.2, 30-39 yaş grubunda \%16.2, 40-49 yaş grubunda \%16.6 oranda saptanmıştır. 20-49 yaş grubundaki hastalar \%54 orana sahip bulunmuştu². Kılınç ve ark. Burdur ilinde acil servise başvuran yaşlıların başvuru nedenleri ve sonuçlarının değerlendirmesi ile ilgili yaptıkları çalışmada 65 yaş ve üzeri nüfusun tüm acil servis başvuruları içindeki oranını \%15 olarak bulmuşlardır ${ }^{3}$. Bizim çalışmamızda genç yaş grubundaki yığılmanın sebepleri, acil servise daha çok başvuru sayısına sahip olunması, atipik semptomlarla da olsa başvuru şikayeti göğüs ağrısı olması, çekilen EKG'lerde daha az patolojik bulgu saptanması sayılabilir. $\mathrm{Bu}$ sebeplerden dolayı çalışmamızdaki yaş dağılımı literatürdeki çalışmalardan farklı çıkmıştır.

Çalışmamıza dahil edilmiş olan hastaların EKG'lerinin ritm analizi incelendiğinde, \%96.1 oranında sinüs ritmi saptanmıştır. Kobza ve ark. gençlerde fizyolojik ve patolojik anomalileri araştırdıkları bir çalışmada \%96 (41.668) oranında EKG normal sinüs ritmi olarak saptanmıştır ${ }^{4}$. Hartman ve ark. acil tıp doktorlarının EKG değerlendirmedeki bilgi düzeyini araştırdıkları çalışmada normal sinüs ritmini tanıma oranı $\% 75$ saptanmıştır ${ }^{5}$. Bizim çalıșmamızda da literatür ile uyumlu olarak ilk değerlendirmeyi yapan tüm hekim grupları dahil ettikleri EKG'lerde aritmiye dikkat etmişlerdir. Yine de en çok aritmik EKG uzman hekim grubunda 29 (\%2.9) hasta ile saptanmıştır. Uzman hekimlerin hastanın eski kardiyak durumunu daha iyi irdeledikleri için bu EKG örneklerini acil patoloji saptanmamış olarak değerlendirmiş olabilecekleri düşünülmüştür.

Çalışmamızda, acil patoloji saptanmayan EKG'lerin incelemesinde, \%3.1 hastada bradikardi, \%5.9 hastada ise taşikardi saptanmıştır. Kobza ve ark. gençlerde EKG bulgularını araştırdıkları çalışmalarında \%19.2 bradikardi, \%3.9 oranında taşikardi saptamıştır ${ }^{4}$. Snoey ve ark. yaptıkları çalışmada acil servis hekimleri ile kardiyoloji hekimlerinin EKG değerlendirilmesi karşılaştırılmış, \%50'ye yakın hatalı değerlendirme saptanmıştır ${ }^{6}$. Fakat bu hatalı değerlendirmelerin sadece $\% 3$ kadarı hastanın tanı ve tedavi sürecini etkileyecek kadar farklı olduğu gösterilmiştir. Yine bu çalışmada EKG değerlendirme parametreleri içinde en çok \%96 oranında uyumluluk kalp hızında saptanmıştır. Çalışmanın sonucunda ise EKG eğitimlerinin sık sık tekrarlanmasını tavsiye etmektedir ${ }^{6}$.

Hiss ve ark. sağlıklı bireylerdeki elektrokardiyografik bulguları inceledikleri kapsamlı bir çalışmada tesadüfi olarak saptanan P dalga morfolojisi anormallikleri (çentikli P dalgası, genlik ve) \%5.7 oranında olmuştur ${ }^{7}$. Çalışmamızda en çok patolojik bulgunun $\mathrm{P}$ dalga morfolojisinde saptanmasının nedeni, sağlıklı erişkin 


\section{Acil Serviste Elektrokardiyografi}

bireylerde ve asemptomatik olarak toplumda s1k bulunması nedeniyle hekimler tarafından çok fazla dikkate alınmaması olabilir.

Pelliccia ve ark. geniş bir popülasyonda anormal EKG bulgularını araştırdıkları bir çalışmada en sık saptadıkları patolojiler $\% 7$ oranında kısa PR aralığı, inkomplet sağ dal bloğu ve erken repolarizasyon paterni olmuştur $^{8}$. Westdrop ve ark. acil servisten taburcu edilen hastaların EKG'lerinin değerlendirmesi ile ilgili yaptıkları bir çalışmada en yaygın hataları; repolarizasyon anormallikleri, dal blokları ve hemibloklarının tespiti olduğunu saptamışlardır ${ }^{9}$. Ahmedali ve ark. acil tıp doktorlarının EKG bulgularının tespit düzeyi ile ilgili yaptıkları bir çalışmada en sık doğru analiz \%96.4 ile normal sinüs ritm EKG'si, en s1k hata ise $\% 66.4$ oran ile 2. derece AV blok tip 1 tanısı koymada saptanmıştır. Literatürde de en sık tanı hatasının ileti problemlerinde yapıldığı bilgisine ulaşılmaktadır. Bu çalışmada da tecrübesi daha az ve daha az EKG eğitimi alanlarda yanlış cevap oranı yüksek çıkmıştır ${ }^{10}$. Kardiyak ileti sistemi problemleri literatürdeki çalışmalarda da gördüğümüz üzere tecrübesi veya EKG üzerine eğitimi daha az hekimlerde sık atlanabilecek bulgulardır. $\mathrm{Bu}$ bağlamda bizim çalışmamızda elde ettiğimiz sonuçlar literatürle uyumludur.

Literatürdeki çalışmalar incelendiğinde sıklıkla acil servis hekimlerinin EKG yorumlama becerisi, yaptıkları majör hatalar araştırılmıştır. Önceden analiz edilmiş EKG örnekleri çalıșma grubuna sunulmuș ve doğru yorumlama becerileri araştırılmıştır. Çalışma yılına göre de yaptıkları hataların kıdem yılıyla olan ilişkisi incelenmiştir. Çoğu zaman da altın standart olarak kabul edilen kardiyoloji hekimlerinin verdikleri cevaplarla kıyaslanmıştır. Çok merkezli bir çalışmada Lee ve ark. trombolitik tedavi için aday 445 AMI olgusunun 21'inin EKG bulgularının AMI'nü gösterdiği halde, acil servis doktorları tarafından tespit edilemediğini ortaya koymuştur ${ }^{11}$. Öncü ve ark. acil tıp asistanlarının EKG değerlendirmesinin doğruluğunu araştırdıkları bir çalışmada kardiyoloji uzmanı tarafından miyokard enfarktüsü ile uyumlu bulgulara sahip olduğu tespit edilen 36 olgunun 22 (\%8.73)'sinin acil tıp asistanlarınca aynı şekilde, 14 (\%5.55)'nün ise farklı şekilde yorumlandığı görülmüştür ${ }^{12}$. Wong ve ark. yaptıkları araştırmada ise anterior ve inferior MI ile ilgili bulguların genellikle doğru tanındığı, posterior MI ile ilgili bulguların tanınmasında yanlışlıkların daha sık olduğu saptanmıştır. Bu bulguların daha sık yanlış yorumlanma nedeni tespit edilemeyen EKG bulgusunun ayna görüntüsü olabileceği ve eğitimlerin daha sık tekrarlanması gerektiğini bildirmişlerdir ${ }^{13}$. Miran ve ark. acil tıp kliniklerinde çalışan yeni başlamış ve 2 yılını tamamlamış hekimlerin temel ve ileri EKG bilgilerini karşılaştırdıkları çalışmalarında, doğru cevap oranı anlamlı derecede 2 yılını bitirmiş doktorlarda yüksek bulunmuştur ${ }^{14}$.
Bizim çalışmamızda acil serviste değerlendirilen ve patoloji saptanmayan EKG'ler incelemeye alınmıştır. Amacımız her EKG parametresi için gözden kaçırılan veya önemsenmeyen patolojilerin sıklığını saptamaktır. $\mathrm{Bu}$ patolojilerin sıklığını da hekimlerin kıdem yılına göre sınıflamaya çalışılmıştır. Araştırma ekibinin analizinden sonra tüm bulgular kardiyoloji hekimi tarafından kontrol edilmiştir. Literatürde araştırmamıza benzer bir çalışmaya rastlamadığımızdan dolayı böyle bir çalışma planlanmıştır. Çalışmamızın tek merkezli bir çalışma olması, EKG'leri değerlendiren hekimlerin farklı kıdem yılına sahip olmaları, bireysel mesleki bilgi ve beceri düzeyindeki farklılıklar, karş1laştıkları hastaların genel başvuru şikayetleri, ek hastalıkları, kullandıkları ilaçları ve muayene ettikleri hasta sayısı farklı olması çalışmamız için kısıtlayıcı faktörler olmuştur.

Sonuç olarak acil servislerde çalışmakta olan tüm hekimlerin ara ara EKG eğitimi alması sağlanmalıdır. Bu eğitimler hem atlanabilecek veya yanlış tanı koyulabilecek EKG'lerin daha doğru değerlendirilmesini hem de klinik olarak önemsenmeyecek patolojik bulguların farkındalık sağlayarak doğru polikliniklere yönlendirip koruyucu sağlık hizmeti verilmesini sağlamaya yardımcı olacaktır.

\section{Kaynaklar}

1. Hoyle RJ, Walker KJ, Thomson G, Bailey M.Accuracy of electrocardiogram interpretation improves with emergency medicine training. Emerg Med Aust. 2017;(19):143-50.

2. Kılıçaslan İ, Bozan H, Oktay C, Göksu E. Türkiye'de Acil Servise Başvuran Hastaların Demografik Özellikleri.Türkiye Acil Tıp Dergisi 2005;(1):5-13.

3. Kılınç A.S, Çatak B,Badıllığlu O, Sütlü S, Dikme Ö, Aydın O, Teker A, Atay E. Acil servise başvuran yaşlıların başvuru nedenlerinin ve sonuçlarının değerlendirilmesi. S.D.Ü. Tıp Fak. Derg. 2012;(4):139-43.

4. Kobza R.,Cuculi F., Abacherli R., Toggweiler S., Suter Y., Frey F., Schmid J. J., Erne P. Twelve-lead electrocardiography in the young: Physiologic and pathologic abnormalities. Heart Rhythm Society 2012; (9):2018-22.

5. Hartman N. D., Wheaton N. B, Williamson K., Quattromani E. N., Branzetti E. B., Aldeen A. Z. A Novel Tool For Assessment of Emergency Medicine Resident Skill In Determining Diagnosis and Management For Emergent Electrocardiograms: A Multicenter Study. The Journal of Emergency Medicine 2016; (51) :697-704.

6. Snoey E.R, Housset B, Guyon P, ElHaddad S, Valty J,Hericord $P$. Analysis of emergency department interpretation of electrocardiograms. J Accid Emerg Med 1994;(3):149-53.

7. Hiss RG., Lamb LE. Electrocardiographic findings in 122,043 individuals.Circulation 1962;947-61.

8. Pelliccia A. ve ark. Prevalence of abnormal electrocardiograms in a large, unselected population undergoing pre-participation cardiovascular screening.European Heart Journal 2008; (27):2006-10.

9. Westdorp E., Gratton M.,Watson W. Emergency department interpretation of electrocardiograms. Annals of Emergency Medicine 1992;(21):541-4. 
10. Ahmedali A, Şener A, Kavaklı H.Ş, Çelik G.K, İçme F, Otal Y, Kahraman A.F, Sezgin Y. Determination of the Level of Emergency Medicine Resident Physicians to Recognize the Electrocardiography Findings. JAEM 2014;(13):108-11.

11. Lee TH, Weisberg MC, Brand DA, Rouan GW, Goldman $\mathrm{L}$.Candidates for thrombolysis among emergency room patients with acute chest pain.Ann Intern Med. 1989;(60):21924.

12. Öncü MR. Acil Tıp Asistanlarınca Yorumlanan Elektrokardiyografilerin Doğruluk ve Güvenirliliğinin Değerlendirilmesi (Uzmanlık Tezi). Bursa Uludağ Üniversitesi Tip Fakültesi , 2008.
13. Wong HE, Kazzi AA, Langdorf MI. Utility of the CORD ECG Database in Evaluating ECG Interpretation by Emergency Medicine Residents. Cal J Emerg Med 2002;(3):59-65.

14. Miran A.S, Değerli V, Parlak İ, Elçin G, Demir Y, Yıldırım E, Coşkun S.Ö, Siliv N. Acil tıp kliniklerinde eğitimine yeni başlayan uzmanlık öğrencileri ile 2 yılını bitirmiş olanların temel ve ileri düzey EKG bilgilerinin karşılaştırılması. İzmir Eğitim ve Araştırma Hastanesi Tıp Dergisi 2015;(19): 60-5. 